Journal of English Language Teaching and Applied Linguistics

ISSN: 2707-756X

DOI: $10.32996 /$ jeltal

Journal Homepage: www.al-kindipublisher.com/index.php/jeltal

JELTAL

\title{
A Contrastive Study of Reflexive verbs in English and French
}

\author{
Dr. Hafissatou KANE 8 (D) \\ Department of English Studies, University Cheikh Anta DIOP of Dakar, Senegal \\ $\triangle$ Corresponding Author: Dr Hafissatou KANE, E-mail: kanehafi@gmail.com
}

\section{ARTICLE INFORMATION}

Received: March 08, 2021

Accepted: April 14, 2021

Volume: 3

Issue: 4

DOI: 10.32996/jeltal.2021.3.4.4

\section{KEYWORDS}

Grammar, reflexives, English,

French, contrastive analysis

\section{ABSTRACT}

This paper describes and compares reflexive verbs in English and French. In collecting the data, a number of books and research works related to the subject have been analysed, using the contrastive method. Results of the analysis indicate that reflexives display a great difference between the two languages. The main observed similarity occurs with the emphatic form. Indeed, the English pronouns "myself", "himself", "ourselves" etc, and their French counterparts moi-même, lui-même, nous-mêmes are used in the same way. Points of differences are presented as follows: while French puts the pronominal clitics me, te, se, nous, vous before the verb, English places pronouns after e.g., se blesser "to hurt oneself". One of most important differences that several verbs take reflexive pronouns in French while their English counterparts don't e.g., se demander "to wonder". It has also been noted that, in English, the same pronouns are used to express both emphatic and non-emphatic forms while French distinctively uses toi-même, elles- mêmes etc. to emphasize; and the pronominal clitics in simple forms. In the reciprocal voice, the English pronouns "each other" and "one another" are less ambiguous than their French corresponding ones. For instance, Nous nous aimons means both "we love ourselves" (reflexivity) and "we love each other / one another" (reciprocity). Finally, it is shown that some English verbs do not appear with reciprocal pronouns but their French equivalents do e.g., "to meet" se rencontrer.

\section{Introduction}

In Fisiak (1985), Contrastive analysis (CA) is defined as a realm of applied linguistics entailed in the comparison and contrast of two or more languages or subsystems of languages in order to determine both the dissimilarities and similarities between them. Such descriptive comparison shows how languages differ in their sound system, grammatical structure, and vocabulary.

The two languages being compared in this paper are English and French through the use of their reflexive verbs. A reflexive verb is used in the grammatical description to refer to a verb or construction where the subject and the object relate to the same entity (Uzoma, 2015). Taxel (2017) states that in grammar a reflexive verb is loosely, a verb whose direct object is the same as its subject. For example, "I wash myself". More generally, a reflexive verb has the same semantic agent and patient (typically represented by the subject and the direct object). For example, the English verb "to perjure" is reflexive, since one can only perjure oneself. In a wider sense, the term refers to any verb whose grammatical object is a reflexive pronoun, regardless of semantics; such verbs are also referred to as pronominal verbs, especially in grammars of the Romance languages (Taxel in Carol 2018:180).

Haspelmath (2019) noted that it is hard to find a reflexive voice marker with no non-reflexive uses. For example, reflexive voice markers commonly have reciprocal uses as in: "They two collided with one another" Haspelmath (2019: 21).

This study focuses on both reflexive and reciprocal verbs, two voices generally found in grammar syllabi of French and English learners. The specific aim of the paper is to compare the morpho-syntactic features of reflexive constructions of the two languages. To that effect, the main objectives of this research is (1) to describe the morphological configurations of these forms,

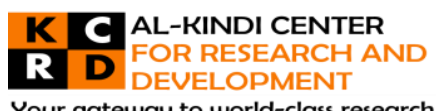

Your gateway to world-class research

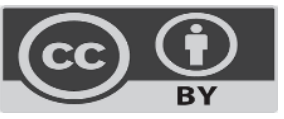

Published by Al-Kindi Center for Research and Development, United Kingdom. Copyright (c) the author(s). This open access article is distributed under a Creative Commons Attribution (CC-BY) 4.0 license 
(2) to indicate their structural features in the sentence and (3) to determine other specific patterns that underlie them. All of this will allow us to point out the differences between the two languages.

Since differences are the leading causes of difficulties while learning a second language, knowing how these constructions are made in each language will help second language learners of both French and English avoid confusion and negative transfers. This will help French-speaking students who are learning English as it is the case in our country, avoid sentences like * $\mid$ ask $\underline{\text { myself }}$ or "we we met instead of "I wonder" and "We met". This can also determine where teaching should mainly be directed.

In the remainder of this paper, I provide some background on the related literature and introduce the research methodology before discussing the details of the analysis. I will finish with some concluding remarks and pedagogical implications of the study.

\section{Research background}

This literature first discusses the role of contrastive analysis in second language teaching and learning.

Lado (1957) states that "we assume that the student who comes in contact with a foreign language will find some features of it quite easy and others extremely difficult. Those elements that are similar to his native language will be simple for him, and those elements that are different will be difficult).

In Wardhaugh (1970) a distinction is proposed between a strong version and a weak version of the contrastive analysis hypothesis. In its strongest formulation, the contrastive analysis hypothesis claims that all the errors made in learning the L2 could be attributed to 'interference' by the L1. However, this claim could not be sustained by empirical evidence that was accumulated in the mid- and late 1970 Salim (2013). It was soon pointed out that many errors predicted by the contrastive analysis were inexplicably not observed in learners' language. Even more confusingly, some uniform errors were made by learners irrespective of their L2. It thus became clear that Contrastive Analysis could not predict all learners' difficulties but was certainly useful in the respective explanation of errors.

Fisiak (1971) asserts that CA has a great pedagogical value precisely in day-to-day teaching in the classroom, and it is a useful technique for presenting language materials to the learner and is one of the characteristic aspects of a method of teaching as well. He believes that the native language (hereafter L1) of the learner is a very powerful element in Second Language Acquisition and one which cannot be removed from the process of learning.

Salim (2013) argues that when the child acquires his / her native language, the child develops the native language behaviour. Gradually, this becomes stronger and stronger. In learning the second language, the learner is very much influenced by his native language behaviour. Where the structure of the two languages is the same or quite similar, no difficulty is anticipated. Where the structure of the second language (L2) differs from (L1), we can predict some difficulty, at least, in learning as well as error in performance. The bigger the differences between the two languages, the greater the difficulty will be. Learning a second language behaviour is essential to overcome these difficulties. In other words, learning a second language involves changing one's native language (L1) behaviour to that of the target language.

In this respect, Salim (2013) believes that contrastive analysis will be useful. It will help to discover the differences between the two languages concerned and predict the difficulties the learners will have to overcome. Teaching will be directed at those points where there are structural differences. This, in turn, determines to a great extent what the learner has to learn and what the teacher has to teach.

Due to this importance of Contrastive Analysis, several languages present in a same area of learners have been compared. For the same reasons, French and English have been compared at different levels.

As mentioned earlier, the present research examines the morpho-syntactic similarities and differences of reflexive and reciprocal constructions in French and English. For that, we need to answer the following questions:

1. What are the constituents of reflexive and reciprocal verbs in French and English?

2. How do they appear in the sentence of both languages?

3. Are there other patterns underlying these morpho-syntactic features?

4. What are the main similarities and differences between the two languages regarding the use of reflexive verbs?

This comparative study is presupposed to reveal a considerable amount of differences between English and French reflexive verbs. This assumption is based on the fact that the two languages often show several dissimilarities in their grammars. 


\section{Research methodology}

In order to compare the French and English reflexive constructions, several research works and grammar books explaining the phenomenon have been used. The analysis also refers to various studies on French and English contrastive grammars. To discuss the reflexive form of each language and their peculiarities, examples have been taken from the existing literature, mainly from Charles Brasart (2015)'s L'Essentiel de la grammaire anglaise and Gabilan (2016)' Grammaire expliquée de l'anglais. Some of the remaining data have been gathered from Michael Swan's (1996) "Practical English Usage". The data of both languages are described and analysed through the contrastive method.

\section{Findings and discussions}

The analysis and discussions of this paper focus on the morphological and structural features of both reflexive and reciprocal constructions.

\subsection{Reflexive verbs / pronominal verbs}

Both in French and English, reflexive verbs can be expressed by means of reflexive pronouns. In English, each grammatical person has a specific reflexive pronoun added to the verb e.g., "She's going to hurt herself!" while in French, only the third persons have a specific reflexive pronoun se as shown in: Elle va se faire mal! The remaining grammatical persons, correspond to the objects. Table 1 shows the French reflexive pronouns also called pronominal clitics and their English corresponding ones.

Table 1: French and English reflexive pronouns

\begin{tabular}{|l|l|l|l|}
\hline \multirow{4}{*}{ Singular } & Person & French & English \\
\hline \multirow{7}{*}{} & $1^{\text {st }}$ & $\mathrm{Me}$ & Myself \\
\cline { 2 - 4 } & $2^{\text {nd }}$ & $\mathrm{Te}$ & Yourself \\
\cline { 2 - 4 } & $3^{\text {rd }}$ & $\mathrm{Se}$ & Himself / itself \\
\cline { 2 - 4 } & & $\mathrm{Se}$ & Herself /itself \\
\cline { 2 - 4 } & & Se & Oneself \\
\hline \multirow{6}{*}{ Plural } & $1^{\text {st }}$ & Nous & Ourselves \\
\cline { 2 - 4 } & $2^{\text {nd }}$ & Vous & Yourselves \\
\cline { 2 - 4 } & $3^{\text {rd }}$ & Se & Themselves \\
\hline
\end{tabular}

What is worth noting from the English sentence "She's going to hurt herself" and its French equivalent Elle va se faire mal is that the two constructions differ at the structural level. While the French pronoun appears before the verb, the English one is placed after. Note that the English pronoun "oneself" is only used with the pronoun "one" or after a verb in the infinitive form.

\subsubsection{English reflexive verbs with "get"}

In English, some reflexive verbs expressing a transition from one status to another are formed with "get" followed by an adjective that can be the past participle form of the verb, while French keeps its se $+V$-inf. Examples of these verbs are given in table 2 .

Table 2: reflexive verbs with "get"

\begin{tabular}{|l|l|}
\hline French & English \\
\hline S'améliorer & To get better \\
\hline S'enrichir & To get rich \\
\hline S'habiller & To get dressed \\
\hline S'y metre & To get started \\
\hline Se facher & To get angry \\
\hline Se marier & To get married \\
\hline Se préparer & To get ready \\
\hline Se salir & To get dirty \\
\hline Se venger & To get even \\
\hline
\end{tabular}

Brasart (2015: 279)

\subsubsection{Reflexive pronouns not used in English}

According to Gabilan (2016), even if both French and English have a reflexive voice, they sometimes use them differently. While certain verbs are used with reflexive pronouns in French, their English equivalents cannot appear. This is why reflexive verbs are much more used in French than English. This difference is one of the main causes of linguistic interference between the two languages. Some of these verbs are presented in table (3) below. 
Table 3: reflexive pronouns not used in English

\begin{tabular}{|l|l|}
\hline French & English \\
\hline S'endormir & To fall asleep \\
\hline Se comporter & To behave \\
\hline Se concenter & To focus, to concentrate \\
\hline Se demander & To wonder \\
\hline Se dépecher & To hurry \\
\hline Se détendre & To relax \\
\hline Se diriger & To head \\
\hline Se laver & To wash \\
\hline Se lever & To get up \\
\hline Se rappeler & To recall \\
\hline Se raser & To shave \\
\hline Se référer & To refer \\
\hline Se réveiller & To wake up \\
\hline Se souvenir & To remember \\
\hline
\end{tabular}

Brasart (2015: 278)

In addition to that, the difference also occurs with verbs expressing midway actions between the active voice and passive voice Gabilan (2016). In English, these verbs appear in a simple form, while in French, they can take two forms. They can be translated with a pronominal clitic as in (1), through another construction like (2) or with another verb as (3) illustrates.

Table 4: Active-Passive midway verbs

\begin{tabular}{|cl|l|}
\hline English & French \\
\hline 1. & A book that reads well, sells well & Un livre qui se lit bien se vend bien \\
\hline 2. She does not photograph well. & Elle n'est pas photogénique. \\
3. My old records still play beautiful. & Mes anciens disques passent toujours bien. \\
\hline
\end{tabular}

Gabilan (2006: 184)

\subsubsection{Resultative constructions not used in French:}

While English frequently uses resultative constructions as in "he reads himself blind", "they shouted themselves hoarse", French completely lacks these forms. To translate the latter, French tends to use the expression à force de or significantly lengthens out the English verbal phrase, to mean the same. Examples (4), (5) and (6) show these different forms.

4. He smoked himself to death.

Il a perdu la vie à force de fumer

5. His parents drove themselves into the ditch.

Ses parents et leur voiture ont fini dans le fossé.

6. She drank herself silly.

Elle a perdu la raison à cause de la boisson.

Gabilan (2016: 185)

\subsubsection{French compound tenses require the auxiliary être "be"}

It has been noted that in compound tenses, French uses the auxiliary verb être "be" which is introduced immediately after the reflexive pronoun followed by the past participle. Contrary to French, the presence of a reflexive pronoun has no impact on the choice of auxiliary verbs in English. In example (7) and (8), the past participle forms of laver "wash" and lever "wake" are preceded by the finite auxiliaries suis "am" and sommes "are".

7. Je me suis lavé "I took my bath"

8. Nous nous sommes levés tard. "We woke up late".

\subsubsection{Emphatic reflexives}

According to Yelena et al. (2016), reflexive or self-pronouns have a dual function in the sentence: they are used as indicators of the category of reflexivity and as intensifiers. In both cases they express the relation between the participants of the event that refer to the same entity. However, if in the first case this relation can be described as that of the subject and the object, the same cannot be said about intensifiers. The intensifiers' role is limited to give an extra force or importance to the elements of the sentence it relates to. 
English uses the same pronouns "myself", "herself", "ourselves" etc. to express reflexivity and to emphasize the element of the utterance it is co-referent with. In French, on the other hand, the reflexive or pronominal morphemes me (myself) te (yourself), nous (ourselves) etc. only indicate reflexivity while emphatic or intensified forms are expressed through pronouns like moi-même (myself), toi-même (yourself) etc. All these intensifying reflexive pronouns are presented in table (6).

Table 6. Emphatic reflexive pronouns

\begin{tabular}{|c|l|l|l|}
\hline \multirow{4}{*}{ Singular } & Person & French & English \\
\cline { 2 - 4 } & $1^{\text {st }}$ & moi-même & Myself \\
\cline { 2 - 4 } & $2^{\text {nd }}$ & toi-même & Yourself \\
\cline { 2 - 4 } & $3^{\text {rd }}$ & lui-même & Himself / itself \\
\cline { 2 - 4 } & & elle-même & Herself /itself \\
\cline { 2 - 4 } & & soi-même & Oneself \\
\hline \multirow{3}{*}{ Plural } & $1^{\text {st }}$ & nous-mêmes & Ourselves \\
\cline { 2 - 4 } & $2^{\text {nd }}$ & vous-mêmes & Yourselves \\
\cline { 2 - 4 } & $3^{\text {rd }}$ & eux-mêmes, elles-mêmes & Themselves \\
\hline
\end{tabular}

The analysis of semantic meanings of these emphatic reflexive pronouns (ERPs) allow (Yelena et al. 2016) to say that they are used to indicate:

- $\quad$ The subject's personal participation in the action or witnessing it personally as in (9).

9. a You want something done right, you have to do it yourself

b. Quand on veut que quelque chose soit bien fait, il faut le faire soi-même

- Confirmation of the actualization of the action by a certain person, so that to exclude any doubt or lack of trust or back the speaker's own statement, as shown in (10).

10. a The doctor said it himself

b. Le médecin l'a dit lui-même.

It has been noted that English and French express these semantic content of emphatic reflexives in a same way. For instance, English has the reflexive pronouns "myself", "yourself", "himself" etc. in (9a) and (10a); and French also uses the equivalent expressions: moi-même, toi-même, lui-même in (9b) and (10b).

Most linguists find that the position of the emphatic reflexive pronoun in the sentence does not imply any substantial change of semantic meaning. For instance, Svartvik finds that "John himself told me" is equal to "John told me himself" as in both cases, it was John, and no one else, who performed the action of telling (Yelena 2016: 431). It means then that the above English sentence can also be "the doctor himself said it" which corresponds to the French Le médecin lui- même l'a dit. This leads to assume that the two languages share the same structures regarding the use of emphatic reflexive pronouns.

Still in Yelena et al. (2016), emphatic reflexive pronouns are also used where the subject of the action performs the action alone, without any help. This is where difference occurs between English and French. In English reflexive pronouns are often preceded "all" and (sometimes) "by" while in French, this idea is materialized by the expression tout seul. This opposition is exemplified in (11a) and (11b) below.

11. a 'Do you need help?' 'No, thanks. I can do it by myself". Swan (1996: 486)
b. 'As-tu besoin d'aide?'
'Non, merci. Je peux le faire tout seul.

The analysis of reflexive verbal phrases between French and English has indicated that the two languages express this voice distinctively. Except for some features they share with the emphatic form, they display all the other mentioned morpho-syntactic aspects.

\subsection{Reciprocal reflexives}

A verb is called reciprocal when it suggests that the people or things represented by the subject of the sentence are doing something to one another. For instance, in "Alphonse and Pétronille hate each other: "Alphone hates Pétronille" and "Pétronille hates Alphonse" Brasart (2015: 279).

\subsubsection{English reciprocal voice less ambiguous}

It has been argued that there is no morphological difference between reflexive and reciprocal forms in French. This is why the following sentence is ambiguous: Nous nous détestons "we hate ourselves" (reflexive voice) or "we hate each other" (reciprocal voice). 
In English, on the other hand, the use of "each other" or "one another" is mandatory to indicate reciprocity. It would be important then for learners to pay attention to the difference that exists in the following sentences.

Table 7: Reciprocal voice less ambiguous in English

\begin{tabular}{|c|l|}
\hline English & French \\
\hline 12. My wife and I hate ourselves. & Ma femme se déteste et je me déteste. \\
13. My wife and I hate each other. & Ma femme me déteste et je la déteste. \\
14. Just kidding, we love each other! & Mais non, voyons, nous nous aimons! \\
15. They beat the crap out of one another & Ils se sont cassé la figure. \\
\hline
\end{tabular}

Brasart (2015: 279)

\subsubsection{Positions of reciprocal pronouns}

In English, "each other" and "one another" can be directly used after the verb as in (16) and (17). They can also be preceded by a preposition and then used as nouns or pronouns as exemplified in (18). These reciprocal pronouns can finally take the genitive form as (19) illustrates.

16. They have decided to stop seeing each other

17. His one and only message is "Love one another"

18. As long as the two of us say the same thing we'll be providing an alibi for each other

19. What quarrel sets them at each other's throats?

Gabilan (2006: 186).

In French, the corresponding forms of "each other" and "one another" can also appear in several forms. They can be simple verbs preceded by a reflexive pronoun e.g., (20). Additionally, they can appear in the two different expressions: l'un(e) pour / de l'autre as in (21); and les un(e)s les autres as exemplified in (22).

20. Décider de ne plus se voir

21. Un alibi l'un(e) pour l'autre

22. Aimez-vous les uns les autres
"To decide not to see each other anymore"

"An alibi for each other"

"Love one another"

Difference finally occurs between the two languages with verbs like "kiss" and "meet". In English, they have reciprocal meaning in their simple form while their French counterparts necessarily take a reciprocal pronoun. For instance, in (23), "kiss" means s'embrasser and in (24), "meet" is translated by se renconter.

23. They kissed Ils se sont embrassés.

24. They met. Ils se sont rencontrés.

\section{Conclusion}

This study has compared the morphosyntactic features of reflexive verbs in English and French. Results of the analysis indicate that there are more differences than similarities. Similarities are mainly observed with emphatic reflexives. English uses pronouns like "myself", "himself", "ourselves" etc, while French also employs the corresponding pronouns moi- même, lui- même, nousmêmes etc. In addition, both languages put their pronouns in a similar position in the sentence, be before or after the verb.

The first noted difference is that while the above-mentioned pronouns express the pronominal voice of verbs in English, French uses the following clitics me, te, se, nous, vous. Also in this case, the English pronoun follows the verb, while in French, it is placed just before it.

Another difference is that while French refers to pronominal verbs with se $+V$-inf form English uses the auxiliary "get" with verbs expressing transitions from on status to another e.g., se marier "to get married". Resultative constructions are also known to be typical of English while the use of the auxiliary être (be) is typical to French compound tenses.

One main difference between the two languages is that certain verbs always appear with a reflexive pronoun in French while English does not require them e.g., se référer "to refer".

Also, contrary to English which uses the same pronouns in both emphatic and non-emphatic reflexive actions, French uses moimême, lui- même etc. while referring to the emphatic form and the pronominal clitics to talk about non-emphatic forms. Still in the emphatic form, the French expression tout seul translates the English "all" or "by" + reflexive pronoun.

Finally, there is a difference between the two languages in the reciprocal voice. While English distinctively uses "each other" and "one another" for reflexivity, French uses the same pronominal morphemes for both reflexivity and reciprocity. Apart from that, some English verbs do not appear with reciprocal pronouns while their French equivalents are necessarily preceded by a pronominal morpheme e.g. "to kiss" s'embrasser, "to meet" se rencontrer. 
As shown, the comparison of reflexive verbs shows a large difference between French and English. These results are in line with several studies contrasting the two languages. It is widely recognized that these differences constitute the major difficulties for second language learners. To overcome this, teaching reflexives, and specially teaching grammar should effectively be focused on these different points.

\section{References}

[1] Astrid, D., Adeline, P., Frank, B. (2013). A Contrastive analysis of present progressive in French and English: Studies in Language, 37(4), 846879.

[2] Carole, E. A. (2018). The French Reflexive Verb and its Urhobo Equivalent: International Journal of Literature, Language and Linguistics, 5(1), 177-186.

[3] Charles, B. (2015). L'Essentiel de la grammaie anglaise: Armand Colin.

[4] Ezeodili, S. U. (2015). On Igbo and French Reflexive Verbs: A contrastive Study: Ivoiriens de recherche linguistique, Institut de Linguistique appliquée, No. 37.

[5] Gabilan, J. P. (2006). Grammaire expliquée de l'anglais. Ellipses Editions Marketing.

[6] Haspelmath, M. (2019). Comparing Reflexive Constructions in the World's languages: MPI-SHH Jena \& Leipzig University.

[7] Kane, H. (2020). Cross-linguistic Differences in English and French VP-ellipsis. International Journal of Linguistics, Literature and Translation, 3(6), 5-13.

[8] Krista, U., Merili, L. (2015). Student's Grammar Mistakes and Effective Teaching Strategies: International Journal of Teaching and Education, $3(1), 70-87$.

[9] Lado, R. (1957). Linguistics across cultures: applied linguistics for language teachers: Ann Arbor, The University Michigan Press, 141p.

[10] Liu, Y. (2014). A Comparative Study of English TENSE and French TENSE. Theory \& Practice in Language Studies, 4(11).

[11] Natalia, A. K. (2018). On Issue of Semantics and Pragmatics of Reflexive Constructions: SHS Web of Conferences 50, 01085 (2018) CIL AIAH2018.

[12] Salim, A. (1991). French and English Noun Phrases: Southern Illinois University Carbondale, Open SIUC.

[13] Salim, J. A. (2013). A Contrastive Study of English-Arabic Noun Morphology: International Journal of English Linguistics, 3(3)

[14] Swan, M. (996). Practical English Usage (Second edition): Oxford University Press.

[15] Yelena, M. Loretta, B. (2016). On Structural and Semantics of Reflexive Constructions in English: Linguistics and Literature Studies, 4 (6): 428432. 